\section{FREE PAPER SESSIONS}

\section{Session 1A: Preparedness}

Chairpersons:

M.A.K. Mattila (Finland)

W.A. Al-Karus (Sultanate of Oman)

\section{Do You Know, What Your Actual Preparedness Is? \\ Matti A.K. Mattila}

Department of Research, Kuopio University Hospital, Kuopio, Finland

Socrates said, "Gnothi se auton!" "You must know yourself!"). It is important to know your own technical skills and tactical preparedness for an occasional accident or disaster. A reliable measure of your knowledge concerning your own personal capabilities is most essential for eventual members or leaders of medical rescue groups. Actually, it is a useful feature for everyone.

Our daily clinical work can guarantee and control our technical skills that would be needed in field traumatology, but practice in tactical operations remains difficult to obtain. Almost every one of us only has an untested imagination of his own ego in making sharp, priority decisions and for adaptation to scarce resources. Instead of depending only upon our imagination, we should have some proof of our level of preparedness.

The use of computer-aided simulations provides a promising opportunity for training in logical decisionmaking for this process. A tactical accident simulation programme (Matimed) has been in use for five years. According to our experience, most physicians and nurses do not master tactics at the expected level. In a multiple casualty situation, you must make a primary survey through all victims before you can start therapeutic procedures and initiate transportation in a correct priority order. In a simulated situation, most trainees stop, however, at the first encountered victim and nearly forget others. In a computer-aided simulation, efforts often are wasted performing non-essential activities without any evidence of an appropriate priority thinking.

In a simulated accident situation, the tactical preparedness of most physicians does not reach the level generally assumed.

We conclude that we live in misleading imaginations of tactical competence. The individual's tactical qualification can be tested easily by applying a simple computer simulation, and also may be improved by frequent training in making tactical decisions challenged by the programme. The significance of priority decisions on victims' outcomes can be demonstrated. The challenge by repetitive training can be maintained by creating a comprehensive library of various simulated multiple casualty situations.

Key Words: computer simulation; decisions; interactive training; preparedness; tactical preparedness; triage

\section{Establishing Disaster Preparedness in a Developing Country \\ Dr. Whaid Ali Alkharusi, FRCS}

Trauma and Rehabilitation Services, Sultanate of Oman

Until 1970, the Sultanate of Oman had no modern facilities to support basic health care needs, let alone face a health disaster. At that time, only one basic missionary hospital, located in Muscat, covered the entire country. The Sultanate of Oman is a nation with a coast line of some $1,600 \mathrm{~km}$ (976 miles) and a geography composed of many different terrain.

In last 21 years, the Sultanate of Oman has taken its place as a fully modern state with adequate facilities in all parameters to combat the effects of disasters. These facilities need to be coordinated to be effective. Other than for a limited period during the early 1970s in the Southern Region, the Sultanate of Oman has not faced a disaster of any consequence, natural or otherwise, during the last 70 years. This long period of security makes onerous the task to alert the community and its leaders aware of the disastrous and deleterious effects of disasters.

This paper discusses:

1) The planning for disaster preparedness and management in the Sultanate of Oman, along with the development of the associated supporting services, such as Emergency Medical Services;

2) The difficulties faced in convincing those responsible, regarding the importance of the planning process, especially due to the lack of experience in local disaster situations. This is increasingly complicated as senior levels of management are faced with prioritizing disaster management with the other needs of a developing country; and

3) The methods used to overcome local and religious beliefs also will be described. An initial effort was made in March of 1996 with the assistance of the international community, but this type of activity needs to have a high priority in order to sustain its momentum.

This paper also will discuss the role played by the Sultanate of Oman in the enhancement of disaster preparedness in the region.

Key Words: disaster management; disaster preparedness; Oman; prioritization

\section{How to Improve International \\ Disaster Relief Activities \\ Yasufumi Asai; Kouji Sakane; Hidetomi Ooi; Aiicbirou \\ Yamamoto; Yasubiro Yamamoto; Muneo Obta; Tomoo \\ Hirakawa; Tutomu Korenaga; Tomohide Atumi* \\ Japanese Disaster Relief, *Nippon Volunteer Network, JICA, Tokyo, Japan}

Purpose: The purpose of this study was to collect information on the systems of international disaster relief activities used by Norway, Germany, and Switzerland, and to exchange views with the people from the governmental and non-governmental organizations (NGOs).

Norwegian Emergency Preparedness System: Relief 
organizations throughout the world have used Norwegian products in a wide variety of situations and under tough climatic conditions. The products are well-known for their quality, and have been utilized and proven functional in the field. Teams of experienced relief workers are available for international responses within 72 hours of receipt of a request for aid. Carefully selected relief goods are available for shipment within 24 hours.

Technical Emergency Relief Service (THW): In situations of a disaster in foreign countries, the German government is able to assist local disaster-relief personnel with its Technical Emergency Relief Service (THW). The THW maintains a Rapid Deployment Search and Rescue (SEEBA) Unit for such cases. The SEEBA consists of THW voluntary specialists who undergo special training and continuing education in order to be prepared for rescue missions in foreign countries.

The Swiss Disaster Relief Unit (SDRU): This units consists of an unarmed corps that provides humanitarian help to foreign countries hit by natural disasters. Immediately following the disaster, six organizations cooperate to form the Swiss Chain of Rescue.

The Japan Disaster Relief Team (JDR): This is the international disaster relief scheme of the Government of Japan, established in 1987 under a law concerning the dispatch of Japan Disaster Relief Teams. The JDR dispatches rescue teams, medical teams, and expert teams. The Japan Medical Team for Disaster Relief (JMTDR) was organized in 1982 to provide emergency medical relief for disasters in developing countries.

Conclusion: The JDR should facilitate closer relationships between NGO groups, must collect more information, and provide them with more resources.

Key Words: Germany; intentional disaster relief; JDR; NGO; Norway; Swiss

\section{Rapid Adduction Motorcycle: A Pilot Project in Athens \\ A. Tulupis; ${ }^{1}$ E. Kontospyru; 1 M. Kokoliu; ${ }^{1}$ C.Bachtis; ${ }^{2}$ M.Vapbiadu ${ }^{2}$}

1. Nursing Office of the HNEMS, 2. Medical Department of the HNEMS, Hellenic National Emergency Medical Service, Athens, Greece

Objectives: Evaluation of a pilot project of the rapid adduction of an emergency physician by a motorcycle.

Methods: We evaluated the first three months of the activity of the Rapid Adduction Motorcycle (RAM), manned with a rescuer and an emergency physician. During this three-month period, the RAM received a total of 150 calls, concerning 154 patients: $7 \%$ of them were classified as severe incidents; 41 of medium severity; and 22 calls were canceled. The average distance covered was $3.5 \mathrm{~km}$ (range: $100 \mathrm{~m}$ to $40 \mathrm{~km}$ ), and the average response time was 4.2 minutes (range: 30 seconds to 20 minutes). Nursing acts provided: venous access, 50 ; vital signs monitoring, 154; placement of tourniquet, 1 ; wound cleaning and dressing, 29; use of scoop-stretcher and vacuum mattress, 5; immobilization with air splints, 10; hemorrhage control, 4; CPR, 8; placement of cervical collar, 6; use of cold pack, 1; placement of orolaryngeal airway, 9 . Conclusions: $U_{p}$ to now, the results of the use of the RAM in Athens are very promising, but further evaluation must be made before we can reach a final conclusion. Key Words: emergency medical and nursing care; emergency physician; rapid adduction motorcycle; rapid adduction vehicle;

\section{The Medical Aspect of Liberia's Complex Emergency in April 1996 \\ D.G. Pyrros, $M D$ \\ Fthiotidos, Athens, Greece}

The author presents his three and one-half months of experience in Monrovia, Liberia, for his third tour, just before the ignition of hostilities. Recruited this time as a demobilization officer with United Nations Observers Mission in Liberia (UNOMIL), he ultimately acted as a Humanitarian Officer for UN-DHA (Department of Humanitarian Affairs), the UN Dispensary Physician, as well as the only expatriate medical doctor in Monrovia for more than two weeks in the middle of one of the worst crises that this war-torn capital ever has faced.

Liberia's history of civil strife with an emphasis on the medical side will be reviewed. The role of International Organizations and non-governmental organizations will be explained and the situation right before the eruption of the hostilities presented.

The immediate changes after the ignition of the new round of civil strife regarding the international community as a whole and UN in particular will be examined. The medical problems for the remaining members of the international community and the Disaster planning that was instituted will be discussed. The pathology that emerged from the various stages of the conflict will be investigated. Information regarding the change from bullet wounds to road traffic accidents as the major cause of deaths will be given. The first signs of an outbreak of cholera and how the response of WHO and others that prevented the worst case scenarios will be probed.

The return of major, non-governmental organizations and other humanitarian players, the unique role that DHA played, and the reluctance of the international community to respond to this emergency will be presented. Conclusions regarding the preparedness of the international community to face this crisis will be drawn. Key Words: cholera; civil strife; disaster; disaster epidemiology; disaster medicine; disaster response; injury types

\section{Session 1B: Preparedness}

Chairpersons:

B.B. Atiyeh (Lebanon/USA)

L. Bernoulli (Switzerland) 